\title{
Para uma avaliação do processamento de palavras sufixadas do português europeu. Desafios da adaptação das provas morfológicas da bateria PAL (Psycholinguistic Assessment of Language)
}

\author{
Cristina Martins \\ Centro de Estudos de Linguística Geral e Aplicada, Universidade de Coimbra \\ Graça Rio-Torto \\ Centro de Estudos de Linguística Geral e Aplicada, Universidade de Coimbra \\ Maria Isabel Festas \\ Faculdade de Psicologia e Ciências da Educação, Universidade de Coimbra
}

\begin{abstract}
Resumo:
A PAL-PORT é uma bateria de provas de avaliação psicolinguística recentemente adaptada para o português (variante europeia) a partir da PAL (Psycholinguistic Assessment of Language), originalmente desenvolvida para a língua inglesa por Caplan (1992). A bateria inclui provas envolvendo, entre outros, aspectos do processamento morfológico. Equacionamos, neste trabalho, os principais problemas levantados pela selecção das palavras derivadas por sufixação que integram as provas de decisão lexical e de produção de palavras afixadas da PAL-PORT. São criticamente discutidos os critérios de selecção destas palavras e, mais precisamente, a forma como diferentes propriedades (com destaque para as morfofonológicas) dos sufixos e das palavras derivadas podem interagir com os modos eventualmente alternativos de processamento (holístico ou (de)composicional) das palavras morfologicamente complexas.
\end{abstract}

\section{Palavras-chave:}

Morfologia derivacional; processamento de palavras complexas; avaliação psicolinguística.

\begin{abstract}
:
The PAL-PORT is the recently adapted European Portuguese version of the Psycholinguistic Assessment of Language (PAL), originally developed for the English language by Caplan (1992). This battery includes subsets of tests pertaining to, amongst others, aspects of morphological processing. In this paper the authors discuss the main challenges faced in selecting the derived suffixed words included in the the PAL PORT's lexical decision test and production of affixed words test. Word selection criteria are critically reviewed considering the manner in which different suffix and derived word properties (especially morphophonological) interact with potentially alternative processing modes (holistic or (de) compositional) of morphologically complex words.
\end{abstract}

Key words:

Derivational morphology, complex word processing, psycholinguistic assessment. 


\section{Introdução}

Pese embora o seu evidente interesse clínico e educacional, é notória a actual carência de provas de avaliação psicolinguística que, envolvendo aspectos do processamento morfológico, sejam adequadas à estrutura da língua portuguesa.

No quadro da recente adaptação para português (variedade europeia) das provas que integram a PAL (Psycholinguistic Assessment of Language $)^{1}$, bateria originalmente desenvolvida para a língua inglesa por Caplan (1992), foi possível dar início a um trabalho que tem por objectivo corresponder a esta necessidade (Festas et al., 2006). Tratando-se de uma bateria que visa avaliar a integridade do funcionamento de diferentes domínios de processamento linguístico (compreensão oral e escrita, produção oral e escrita e leitura oral), a PAL(-PORT) integra 28 provas que selectivamente se centram em aspectos do processamento fonético-fonológico (e, também, no caso de certas provas, em articulação com a ortografia), sintáctico, léxico-semântico e morfológico².

Pretendemos, aqui, equacionar e discutir os problemas centrais levantados pela adaptação, à estrutura do português, de uma das categorias de itens morfologicamente complexos constantes nas provas de decisão lexical e de produção de palavras afixadas da $\mathrm{PAL}^{3}$ : as palavras derivadas por sufixação ${ }^{4}$. Mais especificamente, explicitaremos os desafios colocados pelo recurso, nas provas originais em inglês, a itens cuja estrutura morfológica integra sufixos derivacionais denominados de nível I e de nível II.

1 O processo de adaptação da bateria PAL desenvolveu-se no quadro do projecto Avaliação psicolinguística fina de afasias e outras perturbações da linguagem: uma bateria integrativa de medidas em tempo diferido e em tempo real (RIPD/PSI/63557/2005), coordenado pela Prof. Doutora Maria Isabel Ferraz Festas da Faculdade de Psicologia e Ciências da Educação da Universidade de Coimbra e financiado pela Fundação para a Ciência e Tecnologia.

2 O modelo psicolinguístico subjacente à bateria PAL assume uma arquitectura modular e um processamento serial da informação.

3 As provas de decisão lexical (10 e 23) e de produção de palavras afixadas (13 e 26) existem em pares, distinguindo-se cada membro entre si apenas em função das modalidades de apresentação dos itens ao sujeito e das respectivas respostas: nas provas 10 e 13, a apresentação dos itens é oral e as respostas são também o são; nas provas 23 e 26, os itens são fornecidos por escrito e as respostas são igualmente dadas por escrito.

4 As provas morfológicas da PAL integram igualmente itens flexionados regulares e irregulares, palavras e pseudopalavras, tendo itens destas categorias sido igualmente contemplados nas provas respectivas da PAL-PORT. As questões levantadas pela selecção destes itens não serão, no entanto, objecto de atenção no presente trabalho. 


\section{Sufixos de nível I e de nível II: breve caracterização e relevância psicolinguística}

$\mathrm{Na}$ construção das provas morfológicas da bateria inglesa operou-se com base no princípio explícito de que os sufixos derivacionais do nível I são os que, tendencialmente, têm origem latina, se agregam a bases com esta mesma origem e afectam, frequentemente, a estrutura fonológica dessas bases ( $\operatorname{seren}_{\text {BaseLat }}+i t y_{\text {SufLat }}=s e$ renity). Já os sufixos de nível II, de origem anglo-saxónica, tanto se agregam a radicais simples e nativos ( happy ${ }_{\text {Base }}+$ ness $s_{\text {SufAng-Sax }}=$ happiness), como a radicais já portadores de sufixos de nível I (receptive ${ }_{\text {RadDer(=BaseLat+SufLat) }}+$ ness $s_{\text {SufAng-Sax }}=$ receptiveness), não produzindo, para além do mais, efeitos fonológicos nas bases (Caplan 1992: 220).

Ainda que a consistência dos critérios evocados para sustentar a demarcação entre sufixos derivacionais dos níveis I e II seja passível de observações críticas, a verdade é que a pertinência de uma distinção genérica deste tipo tem vindo a ser reiteradamente assinalada em estudos de natureza diversa, quer linguísticos, quer psicolinguísticos, envolvendo palavras morfologicamente complexas do inglês.

A adequação descritiva da distinção começou por ser evidenciada por linguistas como Chomsky e Halle (1968), Siegel (1974), Aronoff (1976) e Kiparsky (1982). Ainda que não se observe, nas descrições destes autores, completa coincidência quanto à constituição dos inventários de sufixos pertencentes a cada uma das categorias (circunstância que se atribuirá a teorizações e a modelos descritivos de base não idênticos), é possível vislumbrar, nas reflexões existentes, a indicação de propriedades distintivas genéricas e recorrentes dos dois tipos sufixais.

Deste modo, e se os sufixos do tipo I formam, com a respectiva base, um domínio acentual, assim determinando, e em primeiro lugar, as regras de colocação do acento lexical, os de tipo II, não ostentando propriedades comparáveis no plano prosódico, são, por essa razão, e nas palavras de Chomsky e Halle (1968: 84), "“neutral affixes' which characteristically play no role in the placement of stress". As propriedades acentuais de cada tipo de sufixo têm, para além do mais, consequências a outros níveis. Formando, com a base, um domínio acentual, os sufixos de tipo I potenciam a acção de um conjunto de processos fonológicos sobre o material segmental desta, frequentemente conducentes a alterações na respectiva forma fónica (cf. as alterações de timbre vocálico em aspire>aspiration e sane >sanity - ex. de Vannest et al., 2005: 75-). Já os sufixos de tipo II, acentualmente neutros, na acepção vista, não favorecem a acção dos processos fonológicos sobre o material segmental das bases a que se agregam. Nestas circunstâncias, a base tende a ver preservada a sua identidade formal, que não é tipicamente afectada pelo processo derivacional: breath $>$ breathless; bright> brightness; fashion>fashionable (ex. de Vannest et al., 2005: 75). 
Aos argumentos linguísticos evocados, têm vindo juntar-se dados provenientes de investigações psicolinguísticas de natureza vária. A pertinência de se considerar uma distinção entre dois grupos de sufixos derivacionais tem sido sugerida por dados sobre a aquisição linguística de crianças com e sem problemas de desenvolvimento (Windsor e Hwang 1999; Jarmulowicz 2002) e sobre o processamento linguístico de adultos. Os resultados destes últimos trabalhos, envolvendo quer sujeitos normais (Vannest et al. 2005), quer sujeitos portadores de patologias da linguagem (Caplan 1992; Allen e Badecker 2001; Vannest et al. 2005) têm, nomeadamente, contribuído para alimentar a discussão teórica em torno do carácter eventualmente holístico e/ou (de)composicional do processamento das palavras que integram os diferentes tipos de sufixos. Neste sentido, e já no quadro dos modelos que prevêem a coexistência de estas duas vias possíveis de processamento para palavras morfologicamente complexas, a revisão de estudos empíricos empreendida por Caplan (1992: cap. 6) sugere que produtos derivados integrando sufixos de tipo I serão preferencialmente processados de modo holístico, enquanto que produtos derivados portadores de sufixos de tipo II já se prestarão mais facilmente a um processamento (de) composicional.

\section{Da PAL à PAL-PORT. A solução adoptada: apresentação, justificação e limites}

Na construção de um instrumento de avaliação psicolinguística adequada a uma língua românica como o português, e na impossibilidade de fazer respeitar a distinção entre sufixos derivacionais de nível I e de nível II nos exactos termos apresentados por Caplan (sobretudo, mas não só, no que se refere à origem latina $v s$. anglo-saxónica dos sufixos em causa), houve, pois, que ponderar de que modo seria possível preservar a possibilidade de avaliação do efeito eventualmente diferenciado sobre o processamento morfológico, holístico ou (de)composicional, decorrente da distinção entre dois tipos de sufixos derivacionais.

Com este propósito foi fundamental, e antes de mais, ponderar a importância relativa dos factores que, de modo combinado, são convocados para sustentar a distinção entre sufixos derivacionais dos níveis I e II. Na formulação de Caplan (1992: 220), e como se referiu, a distinção assenta em diferenças de ordem etimológica, morfotáctica e morfofonológica:

Latinate suffixes (also called "level I" suffixes) attach to Latinate roots; Anglo-Saxon suffixes (also called "level II" suffixes) attach more freely to many simple, underived words with Latinate suffixes. Latinate suffixes differ from Anglo-Saxon suffixes in other respects as well. They attach be- 
fore Anglo-Saxon suffixes and in many cases they affect the phonological structure of the words to which they are attached. Anglo-Saxon derivational suffixes attach after Latinate suffixed have been attached, and do not influence the sound patterns of the roots to which they are attached (1992: 220).

De entre estes critérios, os de ordem etimológica são aqueles que, evidentemente, não poderiam ser considerados na adaptação, para português, das provas morfológicas da PAL nas quais surgem itens derivados com sufixos de níveis I e II. Argumentar-se-á, para além do mais, que, na perspectiva do sujeito falanteouvinte a testar, o impacto directo de critérios deste tipo será escassíssimo ou mesmo nulo, na justa medida em que a generalidade dos falantes-ouvintes de uma língua natural não tem conhecimentos, explícitos ou implícitos, relativos à origem histórica das palavras e dos seus constituintes morfológicos que possam condicionar o modo como procedem ao seu processamento. Dito isto, será bastante mais plausível pressupor que, para o processamento morfológico a empreender pelo sujeito a testar, serão, antes, potencialmente relevantes critérios de tipo morfotáctico e morfofonológico.

No que concerne à aplicabilidade de critérios morfotácticos para o fim em vista, e mais concretamente dos que especificam a ordem pela qual deverão ser concatenados sufixos derivacionais às respectivas bases de modo a originar produtos gramaticais, esta pressuporia que, entre os itens morfologicamente complexos incluídos nas provas originais da PAL, figurassem os que apresentam radicais derivados por sufixação (como receptiveness $=$ receptive $e_{\text {RadDer(=BaseLat }+ \text { SufLat) }}+$ $\left.n e s s_{\text {SufAng-Sax }}\right)$, pois apenas em relação a esses a questão da ordem de concatenação sufixal se colocaria. Uma análise da constituição morfológica dos itens derivados constantes nas provas originais revelou, contudo, que as respectivas bases de derivação são sempre (com a excepção de um único exemplo ${ }^{5}$ ) radicais não derivados, pelo que a consideração de critérios estritamente morfotácticos não deveria, na tarefa de adaptação das provas morfológicas da PAL para o português, constituir-se como a opção mais adequada.

Assim sendo, tornou-se claro que, na tentativa de estabelecer uma tipologia de sufixos derivacionais útil e produtivo para o fim em apreço, e sem perder de vista os parâmetros considerados por Caplan (1992) na concepção das categorias representadas nas provas originais, deveríamos atender, antes, aos critérios de natureza morfofonológica formulados.

5 Trata-se do item (pseudopalavra) encourageance, o único entre todos os usados nas provas originais da PAL que integra um radical derivado por prefixação: courage $e_{\mathrm{RNom}}>$ encourage $e_{\mathrm{RadDerVb}}+$ ance $_{\mathrm{Suflat}}=$ encourageance $_{\text {PseudopalNom. }}$ 
Como atrás se observou, a divisão dos sufixos derivacionais em dois grupos em função das implicações fonológicas (prosódicas e segmentais) da sua concatenação às respectivas bases também assenta no pressuposto de que os produtos resultantes, pelas características que ostentam, se prestarão preferencialmente a uma forma de processamento sobre outra. Recorde-se que, no contexto dos modelos que prevêm duas vias alternativas para o processamento de palavras morfologicamente complexas, a hipótese é a de que os produtos derivados com sufixos de tipo I se processam preferencialmente de modo holístico e que os produtos derivados com sufixos de tipo II podem prestar-se a um processamento (de)composicional.

A hipótese pode ser justificada pela maior ou menor opacidade formal tendencialmente apresentada pela base morfológica depois de operado o processo derivacional com cada tipo de sufixo, já que, a questão de fundo parece ser a facilidade com que, mediante uma palavra morfologicamente complexa, o falante-ouvinte será capaz de reconhecer (mesmo que por operações implícitas) os respectivos constituintes morfológicos. É plausível postular-se que, na presença de constituintes de base cujas fisionomias morfofonológicas se mantêm relativamente estáveis num dado conjunto de palavras, o falante-ouvinte terá menor dificuldade em reconhecê-los na sua efectiva qualidade de constituintes e até preferir o processamento (de)composicional das palavras morfologicamente complexas em que estão integrados. Segundo o mesmo raciocínio, os constituintes morfológicos que sofrem alterações formais no decurso dos processos de formação lexical mais dificilmente serão reconhecíveis enquanto tais, pelo que se admite que o falante-ouvinte processe a palavra morfologicamente complexa que os integra de um modo preferencialmente holístico ${ }^{6}$.

Pese embora as limitações decorrentes das significativas diferenças estruturais entre a língua inglesa e a língua portuguesa no que concerne às características morfofonológicas aqui consideradas, procurámos, ainda assim, replicar, nas provas morfológicas da versão portuguesa da PAL (PAL-PORT) uma distinção na medida do possível similar à que foi operacionalizada por Caplan (1992) nas provas originais. $\mathrm{O}$ esforço justificava-se face ao interesse repetidamente reconhecido que uma distinção desta natureza tem vindo a revelar para a avaliação das estratégias mobilizadas no processamento de palavras morfologicamente complexas.

6 Dados interessantes e com potencialidades explicativas das tendências descritas encontram-se abundantemente documentados na literatura sobre o processamento diferenciado de itens flexionados regulares (cujos constituintes morfológicos preservam, tipicamente, maior grau de transparência formal) e irregulares (cujos constituintes morfológicos tendem a ser mais opacos e menos reconhecíveis). Sobre esta questão, cf., por exemplo, Ullman et al. 1997; Ullman 2004). 
Não tendo deixado de convocar um conjunto diversificado de critérios linguísticos na selecção dos itens das provas morfológicas (classes sintácticas de produtos e bases, classes semântico-categoriais dos produtos e frequência dos produtos e bases), a solução adoptada na PAL-PORT atendeu, no entanto, e de modo prioritário, às propriedades morfofonológicas de dois grupos de sufixos derivacionais existentes em português.

A ponderação das regras de atribuição do acento principal de palavra em português (Pereira 1999) conduziu-nos à proposta de duas categorias sufixais: por um lado, (i) sufixos que geram produtos acentualmente não marcados (PANM) e, por outro, (ii) sufixos que geram produtos acentualmente marcados (PAM) (Pereira 1999). Sendo o radical (simples ou derivacional) o domínio da atribuição do acento lexical em português, a posição não marcada para o acento é a última vogal desse radical. No caso de um produto derivado acentualmente não marcado, i.e., que integra um sufixo do tipo descrito em (i), será a última vogal do radical derivacional a recebê-lo ([[sérr] RadSimp $\left.a]>\left[[\text { serrán }]_{\text {RadDer }} \text { o]; [flór }\right]_{\text {RadSimp }}>[\text { florál }]_{\text {RadDer }}\right)$, podendo-se, por isto, afirmar que tais sufixos atraem o acento lexical. Já um produto derivado acentualmente marcado resultará da presença de um sufixo que, se for monossilábico ${ }^{7}$, repelirá o acento, fazendo-o recuar para a sílaba que imediatamente antecede esse sufixo (Pereira 1999:144): [[térr $]_{\text {RadSimp }}$ a]>[[térre $]_{\text {RadDer }}$ o/a].

Para além destas características, os sufixos que geram PANM também favorecem, sempre que reunidas as condições fonológicas adequadas, a acção de um conjunto de processos fonológicos sobre o material segmental da base ${ }^{8}$, conducentes a potenciais alterações na respectiva forma: $f[$ ' $\varepsilon]$ bre $+i l=f[1]$ brill; cap['a $]]+i d a d e=c a p a[\mathrm{es}]$ idáde. Pelo contrário, os sufixos monossilábicos na origem de PAM tendem, de modo mais consistente, a preservar as propriedades fonológicas das respectivas bases ${ }^{9}: t[\varepsilon]$ $r r+e o / a=t[' \varepsilon] r r e o / a$.

Outra consequência da adopção do critério acentual nos termos descritos foi a necessidade de escolher, para as provas morfológicas da PAL-PORT, produtos que

7 Alguns dos sufixos geradores de PAM são polissilábicos. Esses atraem o acento lexical, que recairá sobre a sua primeira sílaba (Pereira 1999: 144): [[[calv $]_{\text {Base }}[$ ici $\left.\left.]\right]_{\text {RadDer }} e\right]_{P A M}:\left[\left[[\text { prepara }]_{\text {Base }}[\text { tóri }]\right]_{\text {RadDer }} o\right]_{P A M}$.

8 Entre estes processos, cabe destacar a relevância, neste contexto, da redução das vogais /e/, /E/, /o/, /o/ e /a/ quando em sílaba átona (Mateus e d'Andrade 2000: 134-136). Esclareça-se, pois, que nem sempre as bases às quais se agregam os sufixos na origem de PANM reúnem condições para serem alvo de processos fonológicos que alterem as respectivas formas. Tal quer dizer que as transformações das bases, nestes casos, estão longe de serem obrigatórias.

9 Trata-se, no entanto, e como aqui se afirma, de uma tendência. Casos há, por exemplo, em que se assiste, em derivados desta natureza, a uma alteração no timbre da vogal tónica da base: cal['o] $r>$ cal['o]rico. 
não fossem verbos. Na verdade, tal como tem vindo a ser demonstrado (Pereira 1999; Mateus e d'Andrade 2000), as regras de atribuição do acento principal de palavra em português são sensíveis não só à estrutura morfológica desta, como se viu, mas também à respectiva classe sintáctica ou lexical (Nome, Adjectivo,Verbo). Pereira (1999: cap. 4) evidencia, aliás, dois sistemas de regras de atribuição do acento distintos, um para os verbos e outro para os não verbos, sendo que somente aos não verbos se aplicam aquelas que temos vindo a referir ${ }^{10}$.

Nestas condições, apenas se puderam utilizar, nas provas morfológicas da PALPORT, produtos nominais e adjectivais, mas fizeram-se representar todas as classes de bases possíveis à luz desta constrição. Tendo-se ainda observado que, nas provas originais, a esmagadora maioria dos produtos é heterocategorial ${ }^{11}$ (Rio-Torto 1998: 88) relativamente à base, foram, deste modo, seleccionados itens dos seguintes tipos: nomes deverbais ([medi]ção) e deadjectivais ([fresc]ura), bem como adjectivos deverbais ([lavá]vel) e denominais ([febr]il; [férr]eo).

Nos estudos sobre processamento morfológico disponíveis fica, no entanto, claro que, para além das propriedades morfofonológicas evocadas, outras características, quer dos constituintes morfológicos, quer dos produtos, podem concorrer para potenciar ou, pelo contrário, inibir a reconhecibilidade da natureza composicional de uma palavra morfologicamente complexa. Entre estas características são apontadas a elevada frequência da base, em comparação com a baixa frequência superficial do produto, assim como a elevada produtividade e consistência semântica dos sufixos.

Atendendo à sua importância, estes parâmetros foram igualmente ponderados na escolha dos itens das provas da PAL-PORT. Procurou-se, neste sentido, que os sufixos escolhidos no âmbito das duas grandes categorias obtidas à luz dos critérios acentuais descritos (sufixos que geram PANM e sufixos na origem de PAM) integrassem categorias semântico-categoriais diversas, mas internamente consistentes. Deste modo, ponderámos o recurso a produtos de vários tipos, nomina actionis, nomes agentivos, nomina qualitatis/essendi, nomes instrumentais e adjectivos relacionais, representativos da acção de diferentes operações semânticocategoriais desencadeadas pelo processo sufixal (Rio-Torto 1998).

Ressalve-se, no entanto, que, dadas as características do português, são muito poucos os sufixos derivacionais que possam operar na criação de produtos acentualmente

10 A relevância da classe sintáctica das palavras para o seu processamento também tem vindo a ser assinalada em vários estudos. Cf., por ex. Shapiro et al. 2000.

11 Por heterocategorial entende-se 'de categoria lexical diferente da da base': por exemplo, um nome deadjectival, ou um adjectivo denominal. 
marcados, em contraste com o que acontece no caso dos sufixos que originam produtos acentualmente não marcados. Desta circunstância resulta uma assimetria assinalável no que concerne à diversidade das categorias semântico-categoriais encontrada, em cada uma das duas grandes categorias previstas nas provas morfológicas da PAL-PORT. Na verdade, no grupo dos derivados acentualmente marcados, apenas foram contemplados adjectivos relacionais.

Admitimos, por outro lado, que alguns dos sufixos utilizados serão mais prototípicos dos respectivos grupos semântico-categoriais do que outros e postulamos que diferenças de prototipicidade desta natureza poderão intervir na adopção de estratégias de processamento morfológico dos produtos que estes integram por parte do falante-ouvinte. $\mathrm{Na}$ verdade, esta questão está fortemente articulada com a da produtividade relativa de cada sufixo. Nesta medida, será igualmente plausível pressupor que sufixos mais produtivos em português, como é o caso do agentivo - dor/ $a_{\text {Suff-átono] }}$ (Rodrigues 2008; Almeida 2009), mesmo que geradores de produtos acentualmente não marcados (e eventualmente conducentes a alterações na fisionomia formal das bases a que se agregam), sejam, apesar desta circunstância, relativamente fáceis de reconhecer enquanto constituintes morfológicos. Assim, poderá considerar-se que sufixos, como o agentivo - dor/a, em vez de induzirem um processamento holístico dos produtos que integram (o que se pode postular atendendo às suas propriedades fonológicas), conduzam antes, e já em função da sua elevada produtividade, a um processamento (de)composicional desses mesmos produtos $^{12}$.

O problema da prototipicidade e da produtividade dos sufixos evoca muito claramente o da frequência das bases e dos produtos. No caso da PAL-PORT, optouse por seguir mais estritamente as orientações dadas por Caplan na descrição das provas originais, pelo que o critério da frequência foi apenas considerado na escolha de itens para as de decisão lexical (provas 10 e 23), mas já não no das de produção de palavras sufixadas (provas 13 e 26). Em relação às primeiras, Caplan (1992: 410) adverte que todas as palavras derivadas nelas presentes se deverão construir

$12 \mathrm{O}$ grau diferenciado de produtividade dos sufixos derivacionais foi, de resto, o critério seguido na adaptação destas provas morfológicas ao castelhano (europeu), a única outra língua românica para a qual existe uma versão adaptada da bateria PAL. Os autores, sem, contudo, apresentarem qualquer discussão dos motivos que os conduziram à preferência por esta opção (que é, no entanto, justificável, como se viu), utilizaram duas categorias de sufixos à luz do critério escolhido: (i) sufixos muito produtivos e (ii) sufixos pouco produtivos. Refira-se, no entanto, que também a metodologia seguida na determinação do grau de produtividade dos sufixos do castelhano não é explicitada no manual da bateria (conhecida como RIENAL - Repertorio de instrumentos para la evaluación neurolingüistica de las alteraciones del lenguaje-, Benedet 2006), aventando-se a hipótese de que, para este efeito, tenham eventualmente sido ponderados os dados de frequência lexical existentes para o castelhano que são referenciados no manual da bateria. 
combinando "high frequency stems (...) with afixes" de modo a obter "low frequency complex words". Nas provas 10 e 23 da PAL-PORT, a frequência baixa (igual ou inferior a 27 ocorrências) de todos os produtos e elevada (igual ou superior a 162 ocorrências) das respectivas bases foi verificada na base de frequências lexicais CORLEX (Nascimento 2003).

\section{Trabalho futuro}

É ainda necessário proceder a estudos empíricos com vista à verificação da robustez e do interesse experimental da opção que assumimos na escolha e construção das palavras derivadas constantes nas provas morfológicas da PAL-PORT. Assim sendo, nesta fase do trabalho de adaptação do instrumento de avaliação psicolinguística em causa, apenas poderemos postular, com base nos dados actualmente disponíveis sobre os comportamentos de sujeitos falantes de outras línguas, que factores poderão efectivamente influenciar o tipo de processamento a empreender pelos falantes do português (variedade europeia) de palavras derivadas morfologicamente complexas. Como procurámos explicar, a distinção entre sufixos derivacionais assumida na PAL-PORT levou essencialmente em consideração algumas das respectivas propriedades morfofonológicas, no intuito de manter, e na medida do possível, os critérios que foram explicitamente assumidos na escolha dos itens nas provas originais.

Procurámos evidenciar, no entanto, na discussão problematizadora que aqui empreendemos, que, para além das propriedades morfofonológicas dos produtos e dos seus constituintes morfológicos, será importante não descurar outros factores que os podem caracterizar e contribuir, porventura decisivamente, para o tipo preferencial de processamento deste tipo de palavras morfologicamente complexas. Fica, nomeadamente, claro que, para o aperfeiçoamento de instrumentos desta natureza, é fundamental desenvolver investigação que permita aprofundar o conhecimento sobre as inter-relações entre factores promotores/inibidores da saliência relativa dos constituintes morfológicos. Neste sentido, e como se referiu, será oportuno controlar factores como as frequências das bases, dos produtos e também dos afixos, desenvolvendo metodologias claras que permitam aferir os graus de produtividade/ prototipicidade destes últimos atendendo à respectiva classe semântico-categorial (Ford et. al. 2010).

Mas, mesmo em torno da solução adoptada nesta fase de adaptação das provas morfológicas da PAL, e que passou por privilegiar os critérios morfofonológicos aqui apresentados e discutidos, será oportuno fomentar reflexões críticas. Ponderamos, nomeadamente, a hipótese de que outros factores prosódicos, como os de natureza 
rítmica, se poderão vir a revelar igualmente pertinentes para a determinação da saliência relativa dos constituintes morfológicos que integram as palavras derivadas. Consideremos, em concreto, que nem todos os produtos acentualmente marcados (ou mesmo não marcados) ostentam as mesmas propriedades rítmicas. Predominando o ritmo troqueu e a acentuação paroxítona em português, podemos admitir que os produtos representativos deste formato se assumirão, para o falante-ouvinte, como ritmicamente neutros. Se é verdade que a larga maioria dos sufixos que geram produtos acentualmente não marcados integra produtos desta natureza, também o é, porém, que o sufixo -vel, gerador de produtos acentualmente marcados, conduz, ainda assim, à formação de palavras paroxítonas, ritmicamente neutras. Atendendo a esta característica específica, os produtos derivados em -vel mais se aproximarão dos que integram sufixos geradores de PANM e menos dos que apresentam outros sufixos na origem de PAM, como -ico/a e -eo/a. Estes últimos conduzem à formação de palavras proparoxítonas, de ritmo dáctilo, claramente marcadas em português (quer rítmica, quer acentualmente).

Para já, desconhecem-se os efeitos que poderão ter as propriedades agora evocadas sobre as formas de processamento das palavras derivadas, e, por isso, julgamos de todo o interesse incluir na versão preliminar das provas morfológicas da PALPORT itens que, também deste ponto de vista, são distintos entre si. Espera-se que a avaliação empírica destas provas que se encontra em preparação possa contribuir para elucidar as opções para o seu refinamento futuro.

\section{Referências bibliográficas}

Allen, M. / Badecker, W. (2001): "Morphology: the Internal Structure of Words", em Rapp, B. (ed.), The Handbook of Cognitive Neuropsychology. What Deficits Reveal about the Human Mind, 211-232 (Philadelphia: Psychology Press).

Almeida, A. L. (2009): Produção de nomes agentivos deverbais em português língua materna (L1) por alunos do ensino básico. Tese de Mestrado inédita apresentada à Universidade de Coimbra.

Aronoff, M. (1976): Word Formation in Generative Grammar (Massachusetts: MIT Press).

Benedet, M.J.(2006): Repertorio de instrumentos para la evaluación neurolingüística de las alteraciones del lenguaje (Madrid: Editorial EOS).

Caplan, D. (1992): Language: Structure, Processing, and Disorders (Cambridge, MA.: MIT Press). 
Chomsky, N. / Halle, M. (1968): The Sound Pattern of English (New York: Harper \& Row Publishers).

Festas, I. / Leitão, J. A. / Formosinho, M. D. / Albuquerque, C./ Martins, C. / Branco, A. / André, L. / Lains, J. / Rodrigues, N. / Teixeira, N. (2006): "Uma bateria de avaliação psicolinguística das afasias e de outras perturbações da linguagem para a população portuguesa", em Machado, C. et al. (orgs.), Actas da XI Conferência Internacional Avaliação Psicológica: Formas e Contextos, 719-729 (Braga: Psiquilibrios).

Ford, M. A. / Davis, M. H. / Marslen-Wilson (2010): "Derivational morphology and base morpheme frequency", Journal of Memory and Language 63, 117-130.

Jarmulowicz, L. D. (2002): "English derivational suffix frequency and children's stress judgments", Brain and Language 81, 192-204.

Kiparsky, P. (1982): Lexical Phonology and Morphology, em The Linguistics Society of Korea (ed.), Linguistics in the Morning Calm, 3-91 (Seoul: Hanshin Publishing Co.).

Mateus, M. H. M. / d'Andrade, E. (2000): The Phonology of Portuguese (Oxford: Oxford University Press).

Nascimento, M. F. B. (coord.) (2003): CORLEX. Léxico Multifuncional Computorizado do Português Contemporâneo (Lisboa: Centro de Linguística da Universidade de Lisboa). Disponível em http://www.clul.ul.pt/sectores/ linguistica_de:_corpus/projecto_lmcpc.php [consult. 11.01.2011].

Pereira, I. (1999): O acento de palavra em português. Uma análise métrica. Tese de doutoramento inédita apresentada à Universidade de Coimbra.

Rio-Torto, G. (1998): Morfologia derivacional. Teoria e aplicação ao português (Porto: Porto Editora).

Rodrigues, A. S. (2008): Formação de substantivos deverbais sufixados em Português (München: LINCOM [LINCOM Studies in Romance Linguistics 57]). Inclui CD-Rom.

Shapiro, K. / Shelton, J. / Caramazza, A. (2000): “Grammatical Class in Lexical Production and Morphological Processing: Evidence from a Case of Fluent Aphasia", Cognitive Neuropsychology 17 (8), 665-682.

Siegel, D. (1974): Topics in English Morphology (Massachusetts: MIT Press).

Ullman, M. T. (2004): "Contributions of Memory Circuits to Language: the Declarative/Procedural Model”, Cognition 92, 231-270. 
Ullman, M. T. / Corkin, S. / Coppola, M. / Hickok, G. / Growdon, J. H. / Koroshetz, W. J. / Pinker, S. (1997): “A Neural Dissociation within Language: Evidence that the Mental Dictionary Is Part of Declarative Memory, and that Grammatical Rules are Processed by the Procedural System", Journal of Cognitive Neuroscience 9 (2), 266-276.

Vannest, J. / Polk, T. A. / Lewis, R. L. (2005): "Dual-Route Processing of Complex Words: New fMRI Evidence from Derivational Suffixation", Cognitive, Affective, and Behavioral Neuroscience 5, 67-76.

Windsor, J. / Hwang, M. (1999): “Children's Auditory Lexical Decisions: a Limited Processing Capacity Account of Language Impairment” Journal of Language, Speech and Hearing Research 42, 990-1002. 